\title{
Influence of Ischemic Preconditioning in Myocardial Protection in Patients Undergoing Myocardial Revascularization with Intermittent Crossclamping of the Aorta. Analysis of Ions and Blood Gases
}

\author{
Paulo Manuel Pêgo Fernandes, Fabio Biscegli Jatene, André Felix Gentil, Fabrício Ferreira Coelho, \\ Karina Kwasnicka, N oedir Antonio Groppo Stolf, Sérgio Almeida de O liveira
}

São Paulo, SP - Brazil

\begin{abstract}
Objective - To test the hypothesis that short periods of ischemia may increase the myocardial protection obtained with intermittent crossclamping of the aorta.

Methods - In the control group (18 patients), surgery was performed with systemic hypothermia at $32^{\circ} \mathrm{C}$ and intermittent crossclamping of the aorta. Extracorporeal circulation was used. In the preconditioning group (17 patients), 2 crossclampings of the aorta lasting 3min each were added prior to the intermittent crossclamping of the conventional technique with an interval of 2 min of reperfusion between them. Blood samples for analyses of $\mathrm{pH}$, pCO $\mathrm{C}_{2} \mathrm{pO}_{2}$, sodium, potassium, calcium, and magnesium were obtained from the coronary sinus at the beginning of extracorporeal circulation (time 1), at the end of the first anastomosis (time 2), and at the end of extracorporeal circulation (time 3).
\end{abstract}

Results - No difference was observed in the results of the 2 groups, except for a variation in the ionic values in the different times of blood withdrawal; sodium values, however, remained stable. All patients had a good clinical outcome.

Conclusion - The results of intermittent crossclamping of the aorta with moderate hypothermia were not altered by the use of ischemic preconditioning.

Key words: myocardial revascularization, myocardial preconditioning, ions

Instituto do Coração do Hospital das Clínicas - FMUSP

Mailing address: Paulo Manuel Pêgo Fernandes - InCor - Av. Dr. Enéas C. Aguiar, 44 - 05403-000 - São Paulo, SP, Brazil - E-mail: paulopego@incor.usp.br English version by Stela Maris C. e Gandour
Despite theoretical criticism of the technique of intermittent crossclamping of the aorta with hypothermia at $32^{\circ} \mathrm{C}$, the simplicity of the procedure and its good clinical results have led several surgeons to use it, particularly in myocardial revascularization surgery ${ }^{1,2}$.

In Brazil, Jatene et $\mathrm{al}^{3}$ have been using it since 1969, with good clinical results. A few randomized studies ${ }^{4,5}$ comparing the efficacy of intermittent crossclamping of the aorta with the use of cardioplegic solutions exist, but none of them conclude that one method is superior to the others.

One question about the technique is that the repetition of ischemic episodes, which are individually reversible, may cause cumulative damage resulting in necrosis. Reimer et $\mathrm{al}^{6}$ disproved this concept by showing experimentally that intermittent reperfusion avoids cumulative metabolic deficit and myocardial ischemia with cell death and that the first episode of ischemia reduces the consumption of high energy phosphates in subsequent episodes. Other studies ${ }^{7}$ have shown that short periods of ischemia do not induce irreversible cellular damage and that they do not result in cumulative metabolic, structural, and functional deficits. It has also been reported that, paradoxically, short periods of ischemia increase the tolerance of the heart instead of making it more vulnerable to subsequent ischemic episodes. This induction of tolerance to ischemia is called ischemic preconditioning ${ }^{8}$.

The objective of this study was to assess the influence of ischemic preconditioning on myocardial protection obtained with intermittent crossclamping of the aorta in patients undergoing myocardial revascularization.

\section{Methods}

From October 1998 to May 1999, 35 patients with coronary heart disease who had been referred for myocardial revascularization surgery were divided, in a prospective and randomized way, into 2 groups. The patients in the control 
group were operated upon by 2 surgeons following the conventional myocardial revascularization technique, which uses systemic hypothermia at $32^{\circ} \mathrm{C}$ with intermittent crossclamping of the aorta and extracorporeal circulation. In the other group, called the preconditioning group, 2 short crossclampings of the aorta were added prior to the intermittent crossclamping of the aorta of the conventional technique with an interval of reperfusion between them.

The control group comprised 18 patients, and the preconditioning group 17 patients. The inclusion criteria were as follows: preoperative ejection fraction higher than $30 \%$; not a reoperation; lesion present in at least 2 coronary arteries; predicted use of extracorporeal circulation; no unstable angina at the time of surgery; not an acute phase of myocardial infarction; no need for other associated corrections, such as valvar diseases or left ventricular aneurysm; no need for ventriculotomies.

Fourteen control group patients and 12 preconditioning group patients were males. Ages ranged from 41 to 76 years (mean of 60.6) in the control group and from 41 to 74 years (mean of 65.2) in the preconditioning group.

Cannulation of the ascending aorta and venae cava was used in all patients for installation of extracorporeal circulation. Then, a catheter of the $3 \mathrm{M}$ brand, which is usually used for retrograde cardioplegia, was introduced into the coronary sinus, and blood samples were withdrawn through it. It was only at this time that the surgeon and other members of the medical team knew whether the patient belonged to the control or the preconditioning group.

Crossclampings of the aorta were started after systemic cooling to $32^{\circ} \mathrm{C}$. In the control group, during each crossclamping of the aorta, an anastomosis was performed between the graft and the coronary artery to be revascularized. For each 3-4min of aortic crossclamping, we performed $1 \mathrm{~min}$ of reperfusion. This procedure was used both for distal and proximal anastomoses. In the ischemic preconditioning group, 2 aortic crossclampings of $3 \mathrm{~min}$ of duration each were performed, with an interval of $2 \mathrm{~min}$ of reperfusion between them. After the second interval of reperfusion, the surgery was performed in an identical method as that in the control group. During the last anastomosis, patient's systemic warming was started. By the end of the last anastomosis, the aortic crossclamping was released and extracorporeal circulation was disconnected.

Blood samples were withdrawn from the coronary sinus at 3 different times: at the beginning of extracorporeal circulation in normothermic condition (time 1); immediately after the first anastomosis was performed at $32^{\circ} \mathrm{C}$ (time 2); and at the end of the extracorporeal circulation, again in normothermic condition (time 3 ). The analysis of these blood gas samples was performed with a blood gas analyzer, Radiometer model 620 . Analysis of sodium and potassium was performed with the Radiometer device model ML 100, according to the selective electrode method; the analysis of calcium was performed using the cresolphthalein method with the Integra device (Roche); the analysis of magnesium was performed through the colorimetric method with chlorophosphonazo III, with the Integra device (Roche).

The statistical analysis for comparing the homogeneity of proportions of the two groups was performed with Fisher exact test. Student $t$ test, and the Wilcoxon test were used to compare the quantitative data of the 2 groups.

The significance level established for analysis was $5 \%$, and all calculations were performed using the SAS (Statistical Analysis System). All laboratory measurements and the statistical analysis were performed by persons who were blinded to the groupings.

The study was approved by the scientific committee and the committee on ethics of the Instituto do Coração of the Hospital das Clínicas of the Faculdade de Medicina of the University of São Paulo.

\section{Results}

No difference was observed in the preoperative characteristics age, sex, weight, height, incidence of diabetes mellitus, presence of previous myocardial infarction, presence of bundle-branch block on electrocardiography, and previous unstable angina of the 2 groups, which confirms the homogeneity between the groups.

We performed an average of 3.3 grafts/patient in the control group, and 3.2 grafts/patient in the preconditioning group. In regard to intraoperative characteristics, including the maximum time of aortic crossclamping, sum of the times of aortic crossclamping, number of coronary arteries revascularized, duration of extracorporeal circulation, duration of anesthesia, and the surgeon involved, no difference was observed between the 2 groups of patients (tab. I). In the postoperative period, no patient had signs of intraoperative myocardial infarction, according to assessment with electrocardiography and measurements of CKMB and troponin I.

In regard to blood gases, a drop in the $\mathrm{pH}$ was observed in time 2 as compared with times 1 and $3(\mathrm{p}<0.001)$. A trend toward reversion in this drop was observed in time 3 , but it did not return to the values of time 1 ( $\mathrm{p}<0.001$ ) (fig. 1). The drop in $\mathrm{pH}$ was accompanied by an elevation in $\mathrm{pCO}_{2}$, also with a trend toward reversion not being reached $(\mathrm{p}<0.001)$ and with more negative base excess values. These differences occurred in the same way in both groups.

An increase in partial oxygen pressure occurred in time 2 but not in time $1(\mathrm{p}=0.009)$. In time 3 , a return to the values of time 1 occurred ( $\mathrm{p}=0.438$ ) (fig. 2). These differences took place in the same way in both groups.

No difference was observed between the 2 groups in the sodium, potassium, calcium, and magnesium ions analyzed in the 3 blood samples collected in the coronary sinus in the intraoperative period. Differences, however, were observed in the times. Potassium was elevated in time 2 but not in time $1(\mathrm{p}<0.001)$, dropped in time 3 , but did not reach the values of time 1 ( $\mathrm{p}<0.001)$ (fig. 3 ).

The mean values of the ions throughout the 3 times of measurement occurred as follows: sodium was maintained; calcium was elevated in time 2 but not in time $1(\mathrm{p}<0.001)$; a 


\begin{tabular}{|c|c|c|c|c|c|c|c|c|}
\hline Variable & Group & $\mathrm{n}$ & Minimum & Maximum & Median & Mean & Standard deviation & $\mathrm{P}$ \\
\hline \multirow{2}{*}{$\begin{array}{l}\text { Duration of ECC } \\
\text { (min) }\end{array}$} & 1 & 18 & 75.00 & 215.00 & 118.50 & 121.00 & 29,75 & \multirow[t]{2}{*}{$0,389^{(2)}$} \\
\hline & 2 & 17 & 100.00 & 240.00 & 130.00 & 132.88 & 37,19 & \\
\hline Duration of anesthesia & 1 & 18 & 320.00 & 555.00 & 412.50 & 419.44 & 55,06 & \multirow[t]{2}{*}{$0,542^{(1)}$} \\
\hline$(\min )$ & 2 & 17 & 350.00 & 530.00 & 420.00 & 430.59 & 51,63 & \\
\hline Maximum time of & 1 & 18 & 8.00 & 19.00 & 12.50 & 13.39 & 3,01 & \multirow[t]{2}{*}{$0,150^{(1)}$} \\
\hline Crossclamping (min) & 2 & 17 & 9.00 & 16.00 & 11.00 & 12.06 & 2,25 & \\
\hline Number of & 1 & 18 & 5.00 & 8.00 & 6.50 & 6.28 & 1,07 & \multirow[t]{2}{*}{$0,854^{(2)}$} \\
\hline Crossclampings & 2 & 17 & 3.00 & 11.00 & 6.00 & 6.53 & 2,58 & \\
\hline Total time of & 1 & 18 & 36.00 & 75.00 & 56.50 & 56.28 & 10,81 & \multirow[t]{2}{*}{$0,457^{(1)}$} \\
\hline Crossclamping (min) & 2 & 17 & 24.00 & 79.00 & 46.00 & 52.65 & 17,18 & \\
\hline
\end{tabular}

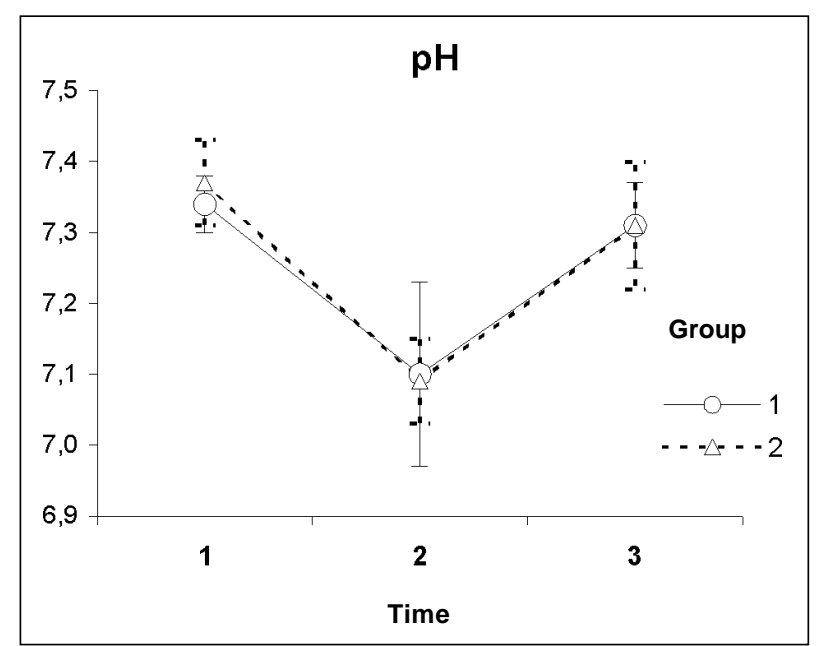

Fig. 1 - Graphic representation of the evolution of the mean values of $\mathrm{pH}$, throughout the 3 times of measurement.

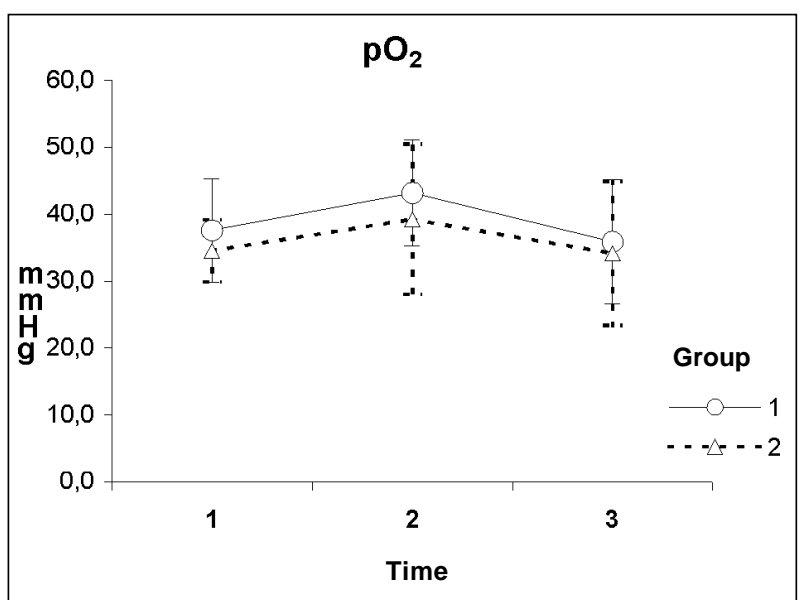

Fig. 2 - Graphic representation of the evolution of the mean values of $\mathrm{pO}_{2}$, throughout the 3 times of measurement.

drop in values occurred in time 3 , which was similar to the increase from time 1 to 2 (fig. 4); and the mean values of magnesium were elevated in time 2 but not in time $1(\mathrm{p}<0.001)$; and time 3 was similar to time $2(\mathrm{p}=0.445)$ (fig. 5$)$. Complete data on these variables are shown in table II.

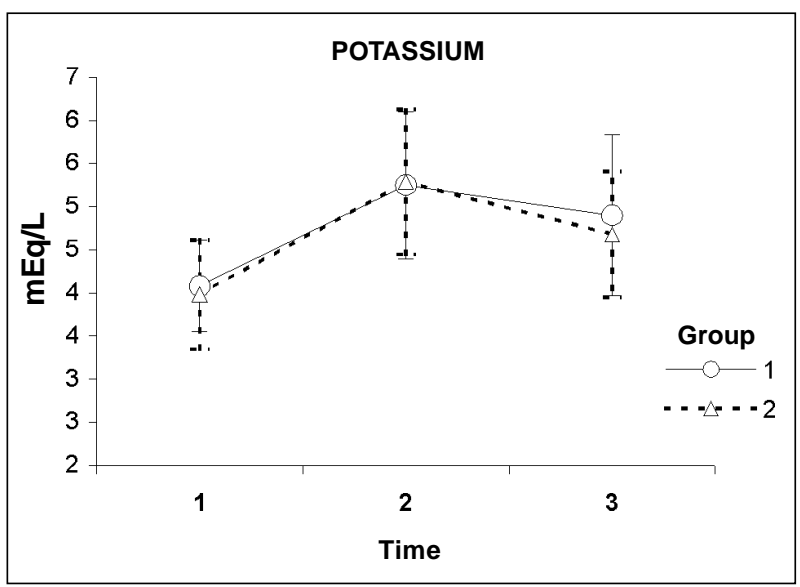

Fig. 3 - Graphic representation of the evolution of the mean values of potassium, throughout the 3 times of measurement.

\section{Discussion}

Currently, ischemic preconditioning is an endogenous adaptive mechanism of the myocardium, induced by short periods of reversible ischemia, which increases heart resistance to a subsequent period of more prolonged ischemia.

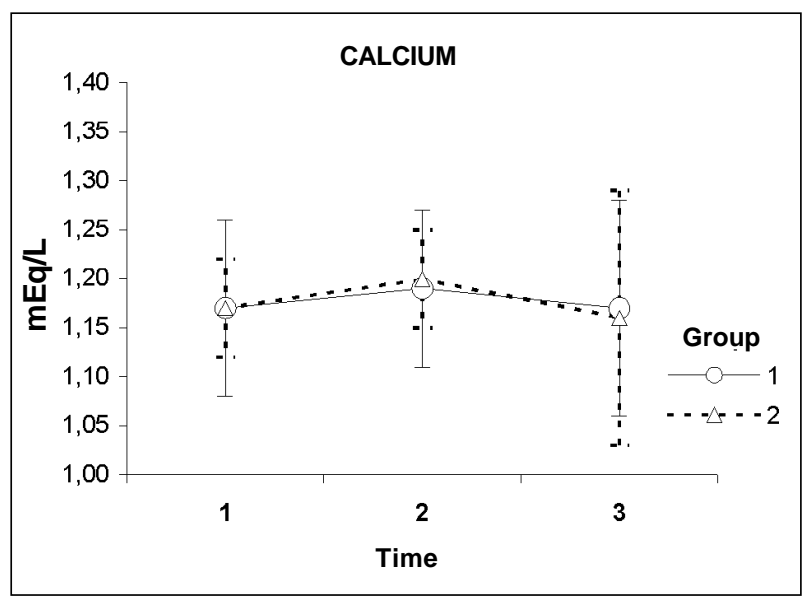

Fig. 4 - Graphic representation of the evolution of the mean values of calcium, throughout the 3 times of measurement. 
This endogenous protection mechanism occurred in all animal species studied ${ }^{9}$, and some authors also suggested its existence in $\operatorname{man}^{10,11}$.

In 1986, Murry et al ${ }^{8}$ were the first to report this phenomenon in a canine model. Since their initial observation, ischemic preconditioning has proved to be the most powerful and reproducible experimental method for delaying the development of myocardial infarction. The beneficial effect of ischemic preconditioning on postischemic recovery of myocardial function results more from limitation of the infarct size than from a reduction in stunning ${ }^{12}$.

Because preconditioning has been recognized as one of the most powerful and reproducible methods for delaying cellular necrosis, an important question to be answered is whether ischemic preconditioning may occur in human beings ${ }^{13}$. At least 4 types of published studies report the occurrence of preconditioning in human beings ${ }^{14}: 1$ ) studies on angioplasty show less alteration in the ST segment and lactate production, when the first episode of angioplasty is compared with the subsequent one ${ }^{15}$; 2) clinical studies suggest that the occurrence of angina prior to myocardial infarction provides beneficial acute effects ${ }^{16} ; 3$ ) acute tolerance to angina may be developed ${ }^{17} ; 4$ ) analysis of human tissues obtained through surgeries shows biochemical and functional properties that reflect a state of preconditioning.

According to Carrol et al ${ }^{17}$, the protection provided by ischemic preconditioning may be divided into 2 phases,

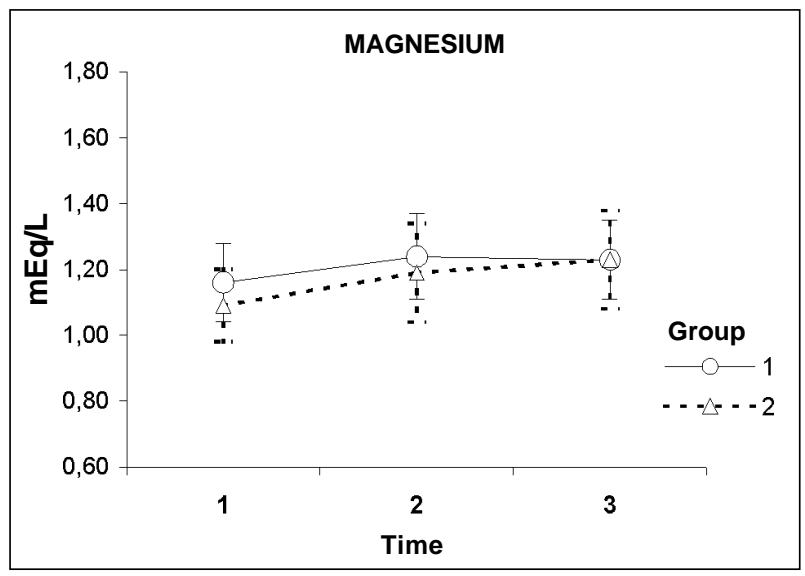

Fig. 5 - Graphic representation of the evolution of the mean values of magnesium, throughout the 3 times of measurement. an earlier phase lasting 1 to 2 hours, and a later one, which begins 24 hours after the initial ischemic event and lasts up to 72 hours. These authors also suggest that, even though these 2 phases of protection are initially determined by similar receptors and paths of intracellular communication, the end target for each of the effects observed may be different. Evidence exists that ionic alterations may take part in the final routes of the ischemic preconditioning mechanism.

During the initial episode of ischemic preconditioning, endogenous substances are formed or secreted, initiating the protective mechanisms of ischemic preconditioning; these and other substances may subsequently maintain protection during the following ischemia. Adenosine, acetylcholine, catecholamines, angiotensin II, bradykinin, and opioids take part in ischemic preconditioning; their quantitative contribution and their effective participation at the beginning or as mediators, however, vary from species to species ${ }^{18}$.

Evidence exists that the end target of the late phase of protection determined by preconditioning is a potassium channel sensitive to ATP ${ }^{17}$. Several studies have shown that adenosine may activate the potassium channel reducing the duration of the action potential, and, therefore, decreasing the use of ATP ${ }^{14}$. This mechanism promotes significant myocardial protection in in vivo and in vitro models; evidence exists that the basic mechanism of increase in tolerance to ischemia during intermittent crossclamping of the aorta is related to the cardioprotective effects of adenosine through stimulation of the A1 receptor ${ }^{19}$.

In addition to adenosine, other hyperpolarizing agents (potassium channel activators) are being studied as alternatives for depolarizing drugs, which are commonly used in cardioplegic solutions. However, these agents have low cardioselectivity and may cause systemic vasodilation before cardioprotective effects are manifested, therefore, hindering their clinical application ${ }^{20}$.

Some researchers ${ }^{21}$ studied the difference between the arterial measurement and that in the coronary sinus of the potassium levels, after release of the aortic crossclamping in a randomized group of 72 patients, who had undergone myocardial revascularization in normothermia and different models of hypothermia. A greater difference was found between the arterial measurement and that in the coronary sinus during the first period of reperfusion than in the subsequent periods. These findings were observed inclu-

\begin{tabular}{|c|c|c|c|c|c|c|c|}
\hline & Control (1) & Precond. (1) & Control (2) & Precond. (2) & Control (3) & Precond. (3) & \\
\hline $\mathrm{pH}$ & $7.34 \pm 0.0$ & $7.37 \pm 0.0$ & $7.10 \pm 0.1$ & $7.09 \pm 0.0$ & $7.31 \pm 0.0$ & $7.31 \pm 0.0$ & p: 0.906 \\
\hline $\mathrm{BE}$ & $-3.2 \pm 2.1$ & $-3.1 \pm 1.7$ & $-8.2 \pm 3.5$ & $-8.3 \pm 2.7$ & $-3.4 \pm 2.6$ & $-3.9 \pm 3.3$ & p: 0.751 \\
\hline $\mathrm{pCO}_{2}$ & $40.3 \pm 6.2$ & $38.0 \pm 5.9$ & $74.5 \pm 23.2$ & $72.7 \pm 7.8$ & $45.5 \pm 9.3$ & $44.5 \pm 7.3$ & p: 0.585 \\
\hline $\mathrm{pO}_{2}$ & $37.5 \pm 7.6$ & $34.5 \pm 4.6$ & $43.1 \pm 7.9$ & $39.2 \pm 11.2$ & $35.8 \pm 9.3$ & $34.1 \pm 10.7$ & p: 0.170 \\
\hline Potassium & $4.08 \pm 0.5$ & $3.98 \pm 0.6$ & $5.25 \pm 0.8$ & $5.29 \pm 0.8$ & $4.9 \pm 0.9$ & $4.68 \pm 0.7$ & p: 0.661 \\
\hline Sodium & $134 \pm 3.0$ & $134 \pm 2.9$ & $133 \pm 3.2$ & $134 \pm 2.7$ & $133 \pm 2.1$ & $135 \pm 3.1$ & p: 0.310 \\
\hline Calcium & $1.17 \pm 0.0$ & $1.17 \pm 0.0$ & $1.19 \pm 0.0$ & $1.20 \pm 0.0$ & $1.17 \pm 0.1$ & $1.16 \pm 0.1$ & p: 0.923 \\
\hline Magnesium & $1.16 \pm 0.1$ & $1.09 \pm 0.1$ & $1.24 \pm 0.1$ & $1.19 \pm 0.1$ & $1.23 \pm 0.1$ & $1.23 \pm 0.1$ & p: 0.335 \\
\hline
\end{tabular}


ding those about potassium levels, and they probably reflect the action of a mechanism of ischemic preconditioning. Years later, one of the authors ${ }^{22}$, reviewing the results, drew attention to the existence of a reduction in the washing of the metabolites after subsequent intervals of ischemia, as a result of the increase in tolerance to ischemia. Even though the washing of metabolites was lower in the hypothermic group than in the normothermic group, the preconditioning effect remained the same even during hypothermia of $25^{\circ} \mathrm{C}$. These data were especially significant for our study, because other authors ${ }^{23}$ have reported that the ischemic preconditioning effect might not occur in situations of hypothermia, even in the mild cases $\left(32^{\circ} \mathrm{C}\right)$.

In our study, the potassium level had an elevation between the beginning of extracorporeal circulation and the first coronary anastomosis, with a drop after the end of extracorporeal circulation, even though not reaching its initial values.

The decrease in the levels of tissular ATP was followed by a significant increase in intracellular $\mathrm{Ca}^{+2}$ levels ${ }^{24}$. Several authors ${ }^{19,25,26}$ suggest that the increase in the intracellular calcium is one of the major determinants of the ischemic lesion, through a calcium-dependent mechanism that activates the catabolic enzymes, leading to irreversible damage of the plasmatic membrane, and determining cellular death.

Catecholamines are known to increase intracellular calcium. If a release of catecholamines occurs during preconditioning, a lower concentration of catecholamines will exist at the end of more prolonged episodes of ischemia. Downey et al ${ }^{27}$ showed that adenosine antagonists block preconditioning. Therefore, the effect of adenosine might be mediated by the inhibition of the release of endogenous catecholamine accompanied by a lower concentration of intracellular calcium.

In addition to the relation between the increase in intracellular calcium and the irreversible lesion of the plasmatic membrane, some authors also suggest that this increase is directly related to a contractile postischemic dysfunction (stunning).

Steenbergen et $\mathrm{al}^{28}$ investigated the ionic alterations in perfused hearts of rats undergoing preconditioning. The 2 study groups underwent $30 \mathrm{~min}$ of global ischemia, and one of the groups was treated with 4 periods of 5-min ischemia with 5-min intervals of reperfusion (preconditioning) at $37^{\circ} \mathrm{C}$ between them. The group undergoing preconditioning had a lower release of intracellular enzymes, a delay in the beginning of the ischemic contracture, and a better functional performance after the period of global ischemia. The group of preconditioned hearts had a significant reduction in the levels of intracellular $\mathrm{H}^{+}$and $\mathrm{Ca}^{+2}$ at the end of the global ischemia period, and a mild but not significant reduction occurred in the increase in intracellular $\mathrm{Na}^{+}$. This last finding may be explained by the thermodynamic differences between the $\mathrm{Na}^{+}-\mathrm{Ca}^{+2}$ exchanger, which exchanges $3 \mathrm{Na}^{+}$ ions for every $2 \mathrm{Ca}^{+2}$ ions.

The use of cardioplegia prior to ischemia proved to be effective in delaying the increase in intracellular calcium and consequent cellular death. Murry et $\mathrm{al}^{8}$ reported that after $40 \mathrm{~min}$ of ischemia, the production of lactate in preconditioned hearts was $40 \%$ lower than that in nontreated hearts. Steenbergen et al ${ }^{28}$ suggest that this reduction in the production of lactate may be due to a lower acidification of the intracellular medium. A lower concentration of hydrogen may reduce intracellular sodium and calcium increase through $\mathrm{Na}^{+}-\mathrm{H}^{+}$and $\mathrm{Na}^{+}-\mathrm{Ca}^{+2}$ exchangers, respectively.

Walker et $\mathrm{al}^{29}$ performed an experiment confirming that right atrial musculature may be preconditioned. These authors showed that the human muscle might be pharmacologically preconditioned with the use of an adenosine A1 agonist. Similarly, Ikonomidis et al ${ }^{30}$ showed that isolated human cardiomyocytes can be preconditioned. Human ventricular myocytes were obtained during surgery and maintained in culture; the cells underwent anoxia for $90 \mathrm{~min}$, followed by 30-min exposure to normal levels of oxygen. The preconditioning of the cells during 20 min of anoxia followed by $20 \mathrm{~min}$ of reoxygenation reduced the cellular lesion caused by a period of subsequent 90 -min ischemia. In addition, the floating material originating from the preconditioned cells had a lower concentration of hydrogen ions, lactate, and lactic dehydrogenase. Therefore, these authors conclude that not only may human myocardial cells be preconditioned, but also this preconditioning occurs independently of interactions with other types of cells.

In our study, ischemia produced by aortic crossclamping caused a drop in $\mathrm{pH}$ accompanied by an elevation in $\mathrm{pCO}_{2}$ and $\mathrm{pO}_{2}$, and also by more negative values of base excess, with a tendency toward normalization after the anastomoses were finished. However, no significant alterations in these variables were observed in the 2 groups studied.

No evidence existed that preconditioning significantly reduced the elevation of calcium levels during the periods of ischemia. A delay occurred in the increase in calcium concentration, which was not avoided. The mean values of sodium were maintained throughout the 3 times of measurement in both groups studied.

It is important to emphasize that, until now, the attenuation in the increase in intracellular calcium through preconditioning has only been shown in experimental studies with rats, and its occurrence in other species is uncertain.

Infusion of magnesium sulfate enhances myocardial recovery after 8-12min of hypoxia in rats. Magnesium sulfate probably causes relaxation of the myocardial fibers during and after the period of hypoxia, in addition to a decrease in the incidence of ventricular fibrillation and asystole ${ }^{31}$.

Ischemic preconditioning obtained with the use of adenosine provides myocardial protection similar to that provided by cardioplegia with potassium supplemented with magnesium. Both techniques promote an enhancement in postischemic recovery from the functional point of view, and they also reduce the extension of the infarct in the aged myocardium ${ }^{32}$.

A study showing the relation between the behavior of magnesium and the efficiency of ischemic preconditioning 
does not exist in the literature. The levels of magnesium had a tendency to increase after the beginning of extracorporeal circulation, and no tendency to decrease at the end of surgery.

We may suppose that the intermittent crossclamping of the aorta, as we and most other surgeons use it, may be an effective form of preconditioning. Another hypothesis is that ischemic preconditioning, in the way it was performed in this study, is either not effective or the protection provided by the intermittent crossclamping of the aorta is already enough, and, therefore, it is difficult to enhance it by ischemic preconditioning. We emphasize that this study was conducted in human beings, and, therefore, periods of ischemia unnecessarily long were avoided. If this, on the one hand, may have occasionally promoted preconditioning, on the other hand, it may have worsened myocardial injury. In fact, some authors ${ }^{15,17,18}$ suggest that ischemic preconditioning in the different protocols did not effectively show a benefit, when they did not worsen myocardial protection. Recent studies ${ }^{20}$ have raised questions about the panacea that has been created about the great benefits of ischemic preconditioning.
One criticism of our study is the inclusion of diabetic patients using sulfonylureas. This was due, at the beginning, to the fact that we ignored the possibility that these drugs could interfere with preconditioning. However, the small number of diabetic patients in our study and their homogeneous distribution between the control and preconditioning groups make us feel confident that the results were not influenced by this factor.

In conclusion, even though the 2 methods of protection cause a certain degree of alteration in the ions and blood gases, the behavior of these parameters was similar in the 2 groups of patients. This indicates that intermittent crossclamping of the aorta with moderate hypothermia was not altered by the preconditioning protocol used. The study of ischemic preconditioning in cardiac surgeries is relatively recent, and its actual benefit is still an open question.

\section{Acknowledgements}

We thank Carine Savalli Reoligolo for the statistical analysis.

\section{References}

1. Flameng W. Intermittent ischemia. Semin Thorac Cardiovasc Surg 1993; 5: 107-13.

2. Kirklin JW, Naftel CD, Blackstone EH, Pohost GM. Summary of a consensus concerning death and ischemic events after coronary artery bypass grafting. Circulation 1989; 79(6 Pt 2): I - 81-91

3. Jatene AD. Late results of aorto coronary saphenous vein by-pass grafts. J Cardiovasc Surg (Torino) 1975; special issue: 91-4.

4. Jatene FB, Ferreira HP, Ramires JA, et al. Estudo comparativo da cardioplegiae do clampeamento intermitente da aorta em cirurgia de revascularização do miocárdio. Arq Bras Cardiol 1990; 54: 105-9.

5. Gerola LR, Oliveira SA, Moreira LF, et al. Blood cardioplegia with warm reperfusion versus intermittent aortic crossclamping in myocardial revascularization: randomized controlled trial. J Thorac Cardiovasc Surg 1993; 106: 491-6.

6. Reimer KA, Murry CE, Yamasawa I, Hill ML, Jennings RB. Four brief periods of myocardial ischemia cause no cumulative ATP loss or necrosis. Am J Physiol 1986; 251 (6 Pt 2): H1306-15.

7. Henrichs KJ, Matsuoka H, Schaper J. Influence of repetitive coronary occlusions on myocardial adenine nucleosides, high energy phosphates and ultrastructure. Basic Res Cardiol 1987; 82: 557-65.

8. Murry CE, Jennings RB, Reimer KA. Preconditioning with ischemia: a delay of lethal cell injury in ischemic myocardium. Circulation 1986; 74: 1124-36.

9. Downey JM, Liu GS, Thornton JD. Adenosine and the anti-infarct effects of preconditioning. Cardiovasc Res 1993; 27: 3-8.

10. Jenkins DP, Pugsley WB, Alkhulaifi AM, Kemp M, Hooper J, Yellon DM. Ischaemic preconditioning reduces troponin $\mathrm{T}$ release in patients undergoing coronary artery bypass surgery. Heart 1997; 77: 314-8.

11. Alkhulaifi AM, Yellon DM, Pugsley WB. Preconditioning the human heart during aorto-coronary bypass surgery. Eur J Cardiothorac Surg 1994; 8: 270-6.

12. Jenkins DP, Pugsley WB, Yellon DM. Ischaemic preconditioning in a model of global ischaemia: infarct size limitation, but no reduction of stunning. J Mol Cell Cardiol 1995; 27: 1623-32.

13. Barry WH. Calcium and ischemic injury. Trends Cardiovasc Med 1991; 1: 162-6.

14. Ragazzi E, Wu S-N, Shryock J, Belardinelli L. Electrophysiological and receptor binding studies to assess activation of the cardiac adenosine receptor by adenine nucleotides. Circ Res 1991; 68: 1035-44.

15. Murphy E, Steenbergen C, LeFurgey A, Lieberman M, London RE. Cytosolic free calcium and miocardial cell injury. In: Lemasters JJ, Hackenbrock CR, Thurman RG, Westerhoff HV (eds). Integration of Mitochondrial Function. New York: Plenum Publishing Corp. 1988: 413-20.

16. Alkhulaifi AM, Jenkins DP, Pugsley WB, Treasure T. Ischaemic preconditioning and cardiac surgery. Eur J Cardiothorac Surg 1996; 10: 792-8.
17. Carroll R, Yellon DM. Myocardial adaptation to ischaemia-the preconditioning phenomenon. Int J Cardiol 1999; 68(suppl 1): S93-101.

18. Downey JM, Cohen MV. Signal transduction in ischemic preconditioning. Z Kardiol 1995; 84(suppl 4): 77-86.

19. Murphy E, Perlman M, London RE, Steenbergen C. Amiloride delays the ischemia-induced rise in cytosolic free calcium. Circ Res 1991; 15: 33-44.

20. Perrault LP, Menasche P. Preconditioning: can nature's shield be raised against surgical ischemic-reperfusion injury? Ann Thorac Surg 1999; 68: 1988-94.

21. Van der Vusse GJ, Van der Veen FH, Flameng W, et al.. A biochemical and ultrastructural study on myocardial changes during aorto-coronary bypass surgery: St. Thomas Hospital cardioplegia versus intermittent aortic cross-clamping at 34 and $25^{\circ}$ C. Eur Surg Res 1986; 18: 1-11.

22. Flameng W. Intermittent ischemia. Semin Thorac Cardiovasc Surg 1993; 5: 107-13.

23. Di Salvo C, Hemming A, Jenkins D, et al. Can the human myocardium be preconditioned with ischaemia under hypothermic conditions? In: Proceedings of the $9^{\text {th }}$ Annual Meeting. Paris: European Association for Cardiothoracic Surgery, 1995: 324.

24. Steenbergen C, Murphy E, Watts JA, London RE. Correlation between cytossolic free calcium, contracturem ATP, and irreverrsible ischemic injury in perfused rat heart. Circ Res 1990; 66: 135-46.

25. Lee HC, Smith N, MahabirR, Clusin WT. Cytossolic calcium transients from the beating mammalian heart. Proc Natl Acad Sci USA 1987; 84: 7793-7.

26. Fox JEB, Goll DE, Reynolds CC, Phillips DR. Identification of two proteins (actin-binding protein and P235) that are hydrolysed by endogenous $\mathrm{Ca}^{++}$- dependent protease during platelet aggregation. J Biol Chem 1985; 260: 1060-6.

27. Downey JM. The role adenosine in preconditioning. J Molec Cell Cardiol 1990; 23(suppl III): S.28.

28. Steenbergen C, Murphy E, Levy L, London RE. Elevation in cytossolic free calcium concentration early in myocardial ischemia in perfused rat heart. Circ Res 1987; 60: 700-7.

29. Walker DM, Walker JM, Pattison C, Pugsley W, Yellon DM. Preconditioning protects isolated human muscle. Circulation 1993; 88(suppl 1): I-138.

30. Ikonomidis JS, Tumiati LC, Weisel RD, Mickle DAG, Li RK. Preconditioning human ventricular cardiomyocytes with brief periods of simulated ischaemia. Cardiovasc Res 1994; 28: 1285-91.

31. Siemkowicz E. Magnesium sulfate solution dramatically improves immediate recovery of rats from hypoxia. Resuscitation 1997; 35: 53-9.

32. McCully JD, Uematsu M, Parker RA, Levitsky S. Adenosine-enhanced ischemic preconditioning provides enhanced cardioprotection in the aged heart. Ann Thorac Surg 1998; 66: 2037-43. 